\section{NUTRITIONAL STATUS AND NUTRITIONAL THERAPY IN PEDIATRIC AND ADOLESCENT PATIENTS SUBMITTED TO AUTOLOGOUS HEMATOPOIETIC STEM CELL TRANSPLANTATION}

\author{
Jéssica Härter ${ }^{1}$, Lauro José Gregianin ${ }^{1,2}$, Luciane Beitler da Cruz ${ }^{1}$
}

Clin Biomed Res. 2020;40(3):167-172 1 Hospital de Clínicas de Porto Alegre. Porto Alegre, RS, Brasil.

2 Departamento de Pediatria, Faculdade de Medicina, Universidade Federal do Rio Grande do Sul.

Porto Alegre, RS, Brasil.

Corresponding author: Jéssica Härter jessicaharter@gmail.com Hospital de Clínicas de Porto Alegre Rua Ramiro Barcelos, 2350. 90035-903, Porto Alegre, RS, Brasil.

\title{
INTRODUCTION
}

Hematopoietic stem cell transplantation (HSCT) is a complex therapeutic procedure whose objective is to induce immunosuppression and facilitate cell grafting and/or remove residual neoplasia through high-dose chemotherapy, with or without radiotherapy ${ }^{1}$. HSCT is often preceded by a conditioning regimen, which may have adverse effects such as gastrointestinal toxicity, and ultimately affect nutritional status. Pediatric cancer patients who undergo HSCT are at even greater nutritional risk due to the combined effects of this procedure, the underlying illness and previous treatments ${ }^{2}$. Malnutrition before and during the transplant is a known predictor of negative outcomes ${ }^{3}$. Thus, nutritional monitoring and the implementation of nutritional therapy (NT) are especially important strategies to counteract the catabolic effects of the disease and the transplant process in pediatric patients, who are in the growth and development phase. Enteral NT seems to offer several benefits, such as decreased adverse effects, costs and length of hospital stay $^{4,5}$, especially with early implementation ${ }^{6}$. Therefore, the aim of this study is to describe the use of NT in children and adolescents submitted to autologous HSCT, and verify changes in nutritional status at hospital discharge after HSCT. 
Härter et al.

\section{METHODS}

A retrospective observational study was conducted on pediatric oncology patients hospitalized for autologous HSTC at the Pediatric Oncology Unit of the Hospital de Clínicas de Porto Alegre (HCPA), RS, Brazil. Inclusion criteria were patients aged 0 to 19 years who were hospitalized at the HCPA between 2010 and 2017. Patients who had no nutritional monitoring or therapy records were excluded from the study. Data were collected from electronic hospital records between June and September 2018. Patient characteristics were examined by collecting data on sex, age, race and type of hospitalization (public or private insurance), using a form created specifically for this study. The disease and oncological treatment were assessed based on the following variables: diagnosis, chemotherapy, radiotherapy and previous oncological surgery. The type of conditioning prior to transplantation was also considered. Nutritional status was evaluated at hospital admission and discharge, according to an institutional protocol that includes measurement of weight and height for the calculation of length/height for age, weight for age, weight for length/height and body mass index for age. Classifications were performed according to the World Health Organization ${ }^{7-9}$ criteria, $^{2}$ using the WHO Anthro and Anthro Plus programs. For analysis, patients were classified into the following categories: underweight/at risk for underweight, normal, overweight/at risk for overweight and obesity. The number of days on exclusive oral intake (OI), enteral tube feeding (ETF), ETF + parenteral nutrition $(\mathrm{ETF}+\mathrm{PN})$ and parenteral nutrition (PN) during hospitalization were also evaluated. For patients who received ETF + PN, the time on NT was calculated by considering the overlapping days and those when only one of methods was used. Patients who received ETF or PN may or may not have had concomitant OI. Oral supplementation was not considered in this study. The length of hospital stay was calculated as the number of days between admission and discharge. The researchers signed a Data Use Agreement prior to conducting the study. This project was approved by the Research Ethics Committee of the Hospital de Clínicas de Porto Alegre, under No. 2,510,615 and CAAE 82639917.3.0000.5327.

\section{Statistical analysis}

Continuous variables are presented as median and interquartile range and categorical variables as frequencies and percentages. The relationship between quantitative and polytomous variables was assessed using the Kruskal Wallis test. The distribution of nutritional status at admission and discharge was compared using the McNemar test. For all tests, values of $p<0.05$ were assumed to be significant. The analyses were conducted using STATA (version 14.0, StataCorp LP, USA).

\section{RESULTS}

Eighty-six patients were initially eligible for the study, but 18 were excluded due to missing data in their medical records, leaving a final sample of 68 patients. Most patients were boys ( $54.4 \%)$, identified as white $(97.1 \%)$ and diagnosed with solid tumors $(89.7 \%)$. Most participants (86.8\%) were also admitted through the public health system (Table 1). The sample was equally divided between patients younger than 5 years and those aged 5 years or older (Table 1 ). Nutritional therapy was required in over half $(52.9 \%)$ of cases, with $22.2 \%$ of these patients receiving ETF, 33.3\% receiving ETF + $\mathrm{PN}$ and $44.5 \%$ receiving $\mathrm{PN}$ only. The type of NT used for the longest duration was ETF + PN. Patients classified as underweight or at risk for underweight received NT for longer than other participant groups (Table 2). The duration of hospitalization was longest for patients who received $\mathrm{ETF}+\mathrm{PN}$ and PN. Though length of hospital stay did not significantly differ between nutritional status groups, patients classified as underweight or at risk for underweight had the highest median number of days in hospital (Table 3). Comparisons of nutritional status revealed a significant reduction in the percentage of at-risk/overweight patients $(p=0.008)$ and an increase in the percentage of at-risk/underweight patients $(p=0.001)$ from admission to discharge (Figure 1). No differences were noted in the frequency of normal weight $(p=0.647)$ or obesity $(p=>0.999)$ (Figure 1). Two patients had missing anthropometric data, prohibiting the assessment of nutritional status at hospital discharge.

Table 1: Patient characteristics $(n=68)$.

\begin{tabular}{lll}
\hline & $\mathbf{n}$ & $\mathbf{( \% )}$ \\
\cline { 2 - 3 } Sex & & $(54.4)$ \\
\hline Male & 37 & $(45.6)$ \\
Female & 31 & $(50.0)$ \\
\hline Age & & $(50.0)$ \\
\hline 5 years & 34 & Continues...
\end{tabular}


Table 1: Continuation

\begin{tabular}{|c|c|c|}
\hline & $\mathbf{n}$ & $(\%)$ \\
\hline \multicolumn{3}{|l|}{ Skin color } \\
\hline White & 66 & $(97.1)$ \\
\hline Non-White & 2 & $(2.9)$ \\
\hline \multicolumn{3}{|l|}{ Type of hospitalization } \\
\hline Public health system & 59 & $(86.8)$ \\
\hline Private insurance & 9 & $(13.2)$ \\
\hline \multicolumn{3}{|l|}{ Diagnosis } \\
\hline Malignant solid tumor & 61 & $(89.7)$ \\
\hline Malignant hematological disease & 7 & $(10.3)$ \\
\hline \multicolumn{3}{|l|}{ Previous surgery } \\
\hline Yes & 54 & $(79.4)$ \\
\hline No & 14 & $(20.6)$ \\
\hline \multicolumn{3}{|c|}{ Number of chemotherapy protocols } \\
\hline One & 36 & $(52.9)$ \\
\hline Two & 26 & $(38.3)$ \\
\hline Three & 6 & $(8.8)$ \\
\hline \multicolumn{3}{|l|}{ Previous radiotherapy } \\
\hline Yes & 13 & $(19.1)$ \\
\hline No & 55 & $(80.9)$ \\
\hline \multicolumn{3}{|l|}{ Conditioning } \\
\hline MEC & 23 & $(33.8)$ \\
\hline BUMEL & 37 & $(54.4)$ \\
\hline Other* & 8 & (11.8) \\
\hline
\end{tabular}

Abbreviations: MEC (Melphalan, Etoposide,Carboplatin); BUMEL (Busulfan, Melphalan). *Other: 5 (Carmustine, Etoposide, Cytarabine, Melphalan), 1 (Melphalan), 1 (Carboplatin, Thiotepa, Etoposide), 1 (Etoposide, Cyclophosphamide, Carboplatin).

Table 2: Duration of nutritional support by type and nutritional status $(n=36)$.

\begin{tabular}{lccc}
\hline & $\mathbf{n}(\%)$ & Median (IQR) & $\boldsymbol{p ~ v a l u e *}^{*}$. \\
\cline { 2 - 4 } Days of NT by route & & & 0.002 \\
ETF & $8(22.2)$ & $13.5(9.5 ; 22)$ & \\
ETF + PN & $16(44.5)$ & $27.5(17.5 ; 35.5)$ & 0.002 \\
\hline Days of NT by nutritional status & $12(33.3)$ & $33.5(23 ; 36)$ & \\
\hline Underweight/At risk & $8(22.2)$ & $14.5(8 ; 23)$ & \\
Normal & $22(61.1)$ & $11(8 ; 12)$ & \\
Overweight/At risk & $6(16.7)$ & - & \\
Obesity & 0 & & \\
\hline
\end{tabular}

Abbreviations: NT (nutrition therapy); PN (parenteral nutrition); ETF(enteral tube feeding), IQR (interquartile range). *Kruskal-Wallis test.

Table 3: Days of hospitalization by route of nutrition and nutritional status $(n=68)$.

\begin{tabular}{lccc}
\hline & $\mathbf{n}(\%)$ & Median (IQR) & $\boldsymbol{p ~ v a l u e *}^{*}$ \\
\cline { 2 - 4 } Days of hospitalization & & & 0.009 \\
ETF & $32(47.1)$ & $34.5(30 ; 41.5)$ & \\
PN & $8(11.8)$ & $28(25.5 ; 39)$ & \\
ETF + PN & $16(23.5)$ & $51.5(28.5 ; 46.5)$ & 0.125 \\
Days of hospitalization & $12(17.6)$ & $43(38 ; 56)$ & \\
\hline At risk/Underweight & & $35(28 ; 44)$ & \\
Normal & $11(16.6)$ & $34(30 ; 62)$ & \\
At risk/Overweight & $39(59.1)$ & $30(30 ; 37)$ & \\
Obesity & $15(22.7)$ & $3(4.5)$ & \\
\hline
\end{tabular}

Abbreviations: OI (oral intake); PN (parenteral nutrition); ETF (enteral tube feeding); IQR (interquartile range). *Kruskal-Wallis test. 


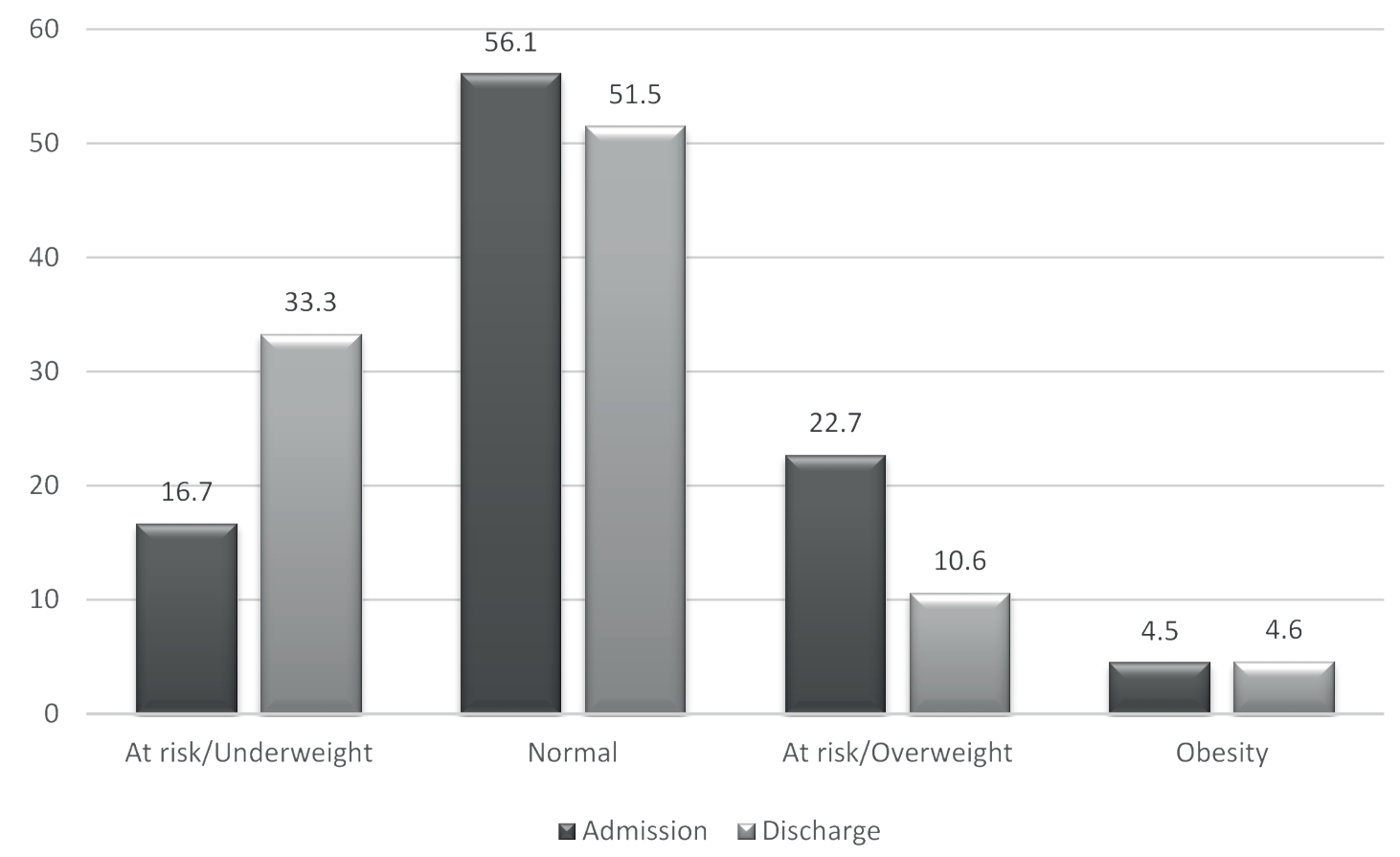

Figure 1: Nutritional status of patients receiving autologous hematopoietic stem cell transplant at hospital admission and discharge $(n=66)$.

\section{DISCUSSION}

In the present study, significant changes in the distribution of nutritional status were observed from admission to discharge in patients who underwent HSCT. Additionally, over half the patients required NT via ETF and/or PN (52.9\%). In a study conducted by Garófolo (2012), the main indications for ETF in patients who underwent autologous transplantation were: inadequate oral intake of food and supplements; insufficient intake of food and supplements with malnutrition or weight loss; and severe malnutrition ${ }^{10}$. The same study also reported that $36 \%$ of patients who underwent autologous HSCT had some degree of malnutrition at admission ${ }^{10}$. In the present study, the percentage of patients who were underweight or at risk for underweight at admission was $16.7 \%$, and increased significantly to $33.3 \%$ at discharge. Though there has been an increase in the prevalence of overweight among healthy children in the general population ${ }^{11}$, those who are hospitalized for transplant are usually in the normal weight range ${ }^{10,12,13}$. This was observed in our study, where most patients were of normal weight in the pre-transplant period $(59.1 \%)$, although this assessment did not consider body composition. The prevalence of obesity in the pre-transplant period was $4.5 \%$, while that of overweight or risk for overweight was $22.7 \%$. According to a study by White et al. ${ }^{12}$, children classified as overweight before autologous or allogeneic transplant have lower survival rates than those in the normal weight range; this finding underscores the importance of an adequate nutritional status in these patients. In a study on NT, Bicakli et al. ${ }^{13}$ demonstrated that pediatric patients who received enteral nutrition during hospitalization for HSTC gained weight, and the median duration of this diet was 21 days, supporting the tolerability of enteral nutrition. These authors also suggest enteral nutrition as a nutritional support strategy for pediatric patients undergoing $\mathrm{HSCT}^{13}$. In another study of pediatric patients receiving autologous HSCT, the authors found that PN could improve nutritional status and also contribute to the recovery of hematopoiesis after the transplant ${ }^{14}$. In our study, PN was the most commonly used method of nutritional support. While $44.5 \%$ of patients who received nutritional support were given PN only, the percentage of those who received PN either alone or in combination with ETF was $77.8 \%$. According to the literature, $\mathrm{PN}$ is associated with a higher risk of infection and complications ${ }^{15,16}$. However, in clinical practice, it is sometimes the best available option for patients with a compromised gastrointestinal tract and other clinical complications. These observations underscore the importance of new studies comparing ETF and PN, as suggested by Bicakli et al. ${ }^{14}$ and also by Garófolo and Nakamura ${ }^{17}$; these authors note that there is little evidence to support nutritional recommendations and nutrition therapy for pediatric patients submitted to HSCT, but encourage the use of ETF based on their review of the literature and practical experience ${ }^{17}$. In the present study, patients 
who received ETF had shorter hospital stays, even when compared to patients on a total oral diet. It should be noted that, in clinical practice, many patients on an oral diet with an indication for ETF or PN during the transplant period cannot receive these treatments due to accidental tube removal, lack of acceptance of the feeding tube, severe thrombocytopenia and/or neutropenia, oral mucositis, and lack of access/ catheter. As such, given the importance of nutritional management during the transplant period, future studies should evaluate the adequacy of $\mathrm{Ol}$ and compare the prescribed and actual dietary intake of patients on an enteral diet, in order to determine the association between these variables and patients clinical outcomes. Few studies in the literature have explored these issues, and only a fraction of these have focused on pediatric patients ${ }^{18,19}$. A study by Andersen et al., for instance, demonstrated that gastrointestinal toxicity is related to poor tolerance of ETF if initiated once the patient has already reduced their food intake, leading to increased indications of $\mathrm{PN}^{5}$. In the present sample, all patients had some degree of gastrointestinal toxicity (data not shown). This may partially explain the high prevalence of PN and the longer hospital stays of patients in this sample. In this context, the early indication of ETF could also impact another relevant variable associated with NT and length of hospitalization: hospitalization costs. $\mathrm{PN}$ is known to be more costly than enteral formulas; therefore, if the early indication of ETF reduces the need for PN, the costs of nutritional support for these patients would also decrease.

\section{CONCLUSION}

Our findings revealed a worsening of nutritional status from admission to discharge in patients submitted to autologous HSCT, as well as a prevalent need for NT in this sample. PN was the most frequently used form of nutritional support, and patients who used ETF diet had shorter hospitalizations. Further studies are needed to identify the most appropriate form of NT and the best time to initiate nutritional support according to the clinical situation. This study had some limitations, such as its retrospective observational design and the number of patients excluded from the analysis due to missing data.

\section{Conflict of Interests}

The authors declare no conflicts of interest.

\section{Acknowledgements}

This research did not receive any specific grants from funding agencies in the public, commercial, or not-for-profit sectors.

\section{REFERENCES}

1. Thomas ED. A history of bone marrow transplantation. In: Blume KG, Forman SJ, Appelbaum FR, editors. Thomas' hematopoietic cell transplantation. 3rd ed. Malden: Blackwell; 2004. p. 3-8.

2. Garófolo A. Diretrizes para terapia nutricional em crianças com câncer em situação crítica. Rev Nutr. 2005;18(4):513-27.

3. Baumgartner A, Hoskin K, Schuetz P. Optimization of nutrition during allogeneic hematologic stem cell transplantation. Curr Opin Clin Nutr Metab Care. 2018;21(3):152-8.

4. Szeluga DJ, Stuart RK, Brookmeyer R, Utermohlen V, Santos GW. Nutritional support of bone marrow transplant recipients: a prospective, randomized clinical trial comparing total parenteral nutrition to an enteral feeding program. Cancer Res. 1987;47(12):3309-16.

5. Andersen S, Kennedy G, Banks M. A randomised controlled comparison of enteral versus parenteral nutritional support post allogeneic haematopoietic cell transplantation. Clin Nutr ESPEN. 2015;10(3):102-6.

6. Sociedade Brasileira de Nutrição Parental e Enteral, Associação Brasileira de Nutrologia. Terapia nutricional no transplante de célula hematopoiética [Internet]. São Paulo: Associação Médica Brasileira; 2011 [cited 2021 Feb 10]. Avaiable from: https://diretrizes.amb. org.br/_BibliotecaAntiga/terapia nutricional_no_transplante_de_celula_ hematopoietica.pdf

7. WHO Multicentre Growth Reference Study Group. WHO child growth standards based on length/height, weight and age. Acta Paediatr Suppl. 2006;450:76-85.

8. Onis $\mathrm{M}$, Onyango AW, Borghi E, Siyam A, Nishida C, Siekmann J. Development of a WHO growth reference for school-aged children and adolescents. Bull World Health Organ. 2007;85(9):660-7.
9. Ministério da Saúde. Orientações para coleta e análise de dados antropométricos em serviços de saúde [Internet]. Brasília (DF); 2011. [cited 2021 Feb 10] Available from: http:// bvsms.saude.gov.br/bvs/publicacoes/ orientacoes_coleta_analise_dados_ antropometricos.pdf

10. Garófolo, A. Enteral nutrition during bone marrow transplantation in patients with pediatric cancer: a prospective cohort study. Sao Paulo Med J. 2012;130(3):159-66.

11. Organización de las Naciones Unidas para la Alimentación y la Agricultura, Organización Panamericana de la Salud. América Latina y el Caribe: panorama de la seguridad alimentaria y nutricional: sistemas alimentarios sostenibles para poner fin al hambre y la malnutrición [Internet]. Santiago: Organización de las Naciones Unidas para la Alimentación y la Agricultura; 2017 [cited 2021 Feb 10]. Available from: http://www.fao.org/3/a-i6747s.pdf. 
12. White M, Murphy AJ, Hallahan A, Ware RS, Fraser C, Davies PSW. Survival in overweight and underweight children undergoing hematopoietic stem cell transplantation. Eur J Clin Nutr. 2012;66(10):1120-3.

13. Bicakli DH, Yilmaz MC, Aksoylar S, Kantar M, Cetingul N, Kansoy S. Enteral nutrition is feasible in pediatric stem cell transplantation patients. Pediatr Blood Cancer. 2012;59(7):1327-9.

14. Wedrychowicz A, Spodaryk M, Krasowska-Kwiecień A, Goździk J. Total parenteral nutrition in children and adolescents treated with high-dose chemotherapy followed by autologous haematopoietic transplants. Br J Nutr. 2010;103(6):899-906.

15. Rzepecki P, Barzal J, Oborska S. Blood and marrow transplantation and nutritional support. Support Care Cancer. 2010;18(Suppl 2):S57-65

16. Guièze R, Lemal R, Cabrespine A, Hermet E, Tournilhac O, Combal C, et al. Enteral versus parenteral nutritional support in allogeneic haematopoietic stem-cell transplantation. Clin Nutr. 2014;33(3):533-8.

17. Garófolo A, Nakamura CH. Terapia nutricional de pacientes com câncer infantojuvenil submetidos a transplante de células-tronco hematopoiéticas. Rev Bras Cancerol. 2018; 64(3):373-81.

18. Koç N, Gündüz M, Tavil B, Azik MF, Coşkun Z, Yardımcı H, et al. Beneficial effect of the nutritional support in children who underwent hematopoietic stem cell transplant. Exp Clin Transplant. 2017;15(4):458-62.

19. Bechard LJ, Guinan EC, Feldman HA, Tang V, Duggan C. Prognostic factors in the resumption of oral dietary intake after allogeneic hematopoietic stem cell transplantation (HSCT) in children. JPEN J Parenter Enteral Nutr. 2007;31(4):295-301. 